\title{
Effect of nerve growth factor on the proliferation in newborn bovine testicular Sertoli cells
}

\author{
Qiaoge Niu, Maosheng Cao, Chenfeng Yuan, Yuwen Huang, Zijiao Zhao, Boqi Zhang, \\ Xin Wang, Yameng Wei, Wenjing Fan, Xu Zhou and Chunjin LiD \\ College of Animal Sciences, Jilin University, Changchun, Jilin, China \\ Correspondence should be addressed to X Zhou or C Li; Email: xzhou65@vip.sina.com or Ilcjj158@163.com
}

\begin{abstract}
Nerve growth factor (NGF) has been proved to play important roles in male reproductive physiology, but the molecular mechanisms of NGF action remain unclear. In this study, the effects of NGF on the growth of newborn bovine testicular Sertoli (NBS) cells and the related signaling pathways were investigated. The NBS cells were treated in vitro with NGF $(100 \mathrm{ng} / \mathrm{mL})$ for $18 \mathrm{~h}$. The expression levels of cell proliferation related genes, INHBB, and cytoplasmic specialization related gene were determined using real-time PCR and Western blot. The roles of PI3K/AKT and MAPK/ERK pathways in NGF-induced cell proliferation were investigated. It was found that NGF regulates proliferation and function of NBS cells via its receptor NTRK1 by activating the PI3K/ATK and MAPK/ERK signaling pathways. The study will help to further understand the role of NGF in male reproduction and provide new therapeutic targets for reproductive dysfunctions in male animals.

Reproduction (2020) $\mathbf{1 6 0} 405-415$
\end{abstract}

\section{Introduction}

In the testes, Sertoli cells act as spermatogenic mother cells, which function to nourish, protect, support, directly control the microenvironment of spermatogenesis, and guide the process of primordial germ cells in the seminiferous tubules toward sperm development (Griswold 1998). INHBB that is mainly secreted by Sertoli cells is used as a marker of testicular cell maturation, and it has a negative feedback regulation effect on follicle stimulating hormone (FSH) secretion (Petersen et al. 1999, Jain \& Halder 2012). Clinically, serum INHBB expression is used as an endocrine marker for spermatogenesis and testicular function that can be correlated with male fertility. (Illingworth et al. 1996, Hipler et al. 2001, Pierik et al. 2003).

The formation of mature junctions in testicular Sertoli cells is a prerequisite for spermatogenesis, and adjacent Sertoli cells are joined into a complex that forms a typical adhesion junction and ectoplasmic specializations (ES). ES is an atypical type of adhesion junction in the testis that connects actin and transmembrane molecules together by vinculin $(\mathrm{VCL})$, which is localized to the actin filament layer (Pfeiffer \& Vogl 1991, Wong et al. 2008).

Long-term studies have shown that Sertoli cells in mammals after puberty are in a terminally differentiated state, without division or proliferation. However, studies have also isolated human primary Sertoli cells from adult testes and found that primary Sertoli cells can be rapidly proliferated and have corresponding cellular functions under optimal conditions in vitro (Chui et al. 2011). In this pilot study, we isolated functional newborn bovine testicular Sertoli cells. In vitro proliferation of Sertoli cells provides an important reference for the study of male infertility and reproductive toxicology.

Nerve growth factor (NGF) is one of the first neurotrophic factors to be found. It is a protein that acts mainly by binding to its high-affinity receptor tyrosine kinase receptor A (NTRK1) and maintains neuronal differentiation and synaptic stability in the peripheral and central nervous systems (Zhang et al. 2000, Attiah et al. 2003). NGF is thought to promote cell proliferation and differentiation and regulate angiogenesis. In inflamed organs, NGF can help recruit inflammatory cells by increasing adhesion factors (Raychaudhuri et al. 2001, Cantarella et al. 2002). PI3K/AKT and MAPK/ERK signaling pathways are important molecular pathways in cells and both play important roles in cell proliferation. NGF can promote the proliferation and differentiation of rat myoblasts in vitro by activating the PI3K/AKT and MAPK/ERK signaling pathways (Rende et al. 2000).

In the testis, the widespread presence of NGF can be detected in the epididymal sperm, and studies have used immunohistochemistry to obtain positive staining for NGF in the seminal vesicle epididymis and testis of male Japanese macaques (Jin et al. 2006). Gene expression of NGF and NTRK1 was detected in the reproductive organs 
of male rabbits (i.e. the testes, prostate and seminal vesicles). The prostate may be the main source of this neurotrophin in the rabbit reproductive system. NGF is involved in testicular development and spermatogenesis in rabbits. In addition, large amounts of NGF in semen may induce ovulation (Maranesi et al. 2015). Studies have also shown that the content of NGF and its receptor, NTRK1, in semen determines the semen quality. NGF expression levels are highly positively correlated with the mitochondrial membrane potential of pure semen samples, and higher NGF expression levels indicate better semen quality (Parthipan et al. 2017). Reports have also directly indicated that NGF regulates sperm acrosome reactions and activates sperm motility, which is important in bovine sperm motility and apoptosis (Jin et al. 2010, Li et al. 2010). In addition to its expression in testicular Sertoli cells, NGF, as an important testicular growth factor, is expressed in various other testicular cells, such as Leydig cells, spermatogonia and spermatocytes (Li et al. 2005). However, the specific mechanism of NGF action on a single type of cells in the testis is not well understood.

The aim of this study was to investigate the role and mechanism of NGF in testicular Sertoli cells. In our preliminary tests, we successfully detected the expression of NGF and its receptor, NTRK1, using immunofluorescence. This study explored stimulation of cell proliferation and cell function by NGF, focusing on two molecular pathways, PI3K/AKT and MAPK/ERK. To further explore whether NGF affects Sertoli cells via the $\mathrm{PI} 3 \mathrm{~K} / \mathrm{AKT}$ or MAPK/ERK pathway, we first determined whether NGF activates AKT or ERK phosphorylation. The results of this study will help further explain male testicular hypoplasia and spermatogenic disorders.

\section{Materials and methods}

\section{Newborn bovine testicular Sertoli cell culture}

The Sertoli cells used in this experiment were isolated by Shanghai Fu Life Industry Co., Ltd from newborn Holstein bovine testes using a differential adhesive method under sterile conditions. After being subcultured and amplified, vials of the cells were frozen in a liquid nitrogen cryofreezer for later use.

The cells were isolated as follows. Testicular tissue was obtained from newborn calves, rinsed twice with normal saline, and quickly rinsed three times with phosphate buffered saline (PBS). After removing the white film, the seminiferous tubules were cut into $1 \mathrm{~mm}^{3}$ sections and placed in $15 \mathrm{~mL}$ centrifuge tubes. Next, $5 \mathrm{~mL}$ of $1.0 \mathrm{mg} / \mathrm{mL}$ collagenase IV/DNase solution (Sigma) was added using the thermostatic shaker set at $34^{\circ} \mathrm{C}$, shaking 110 times $/ \mathrm{min}$ for $20 \mathrm{~min}$. The tissues were then washed with Dulbecco's modified Eagle's medium (DMEM)/highglucose (HyClone, South Logan, UT, USA), then $2.5 \mathrm{mg} / \mathrm{mL}$ trypsin was added and the tissue digested at $34^{\circ} \mathrm{C}$ for $20 \mathrm{~min}$. This process continued with the shaker under the same conditions. After digestion, the mixture was filtered through a $100 \mu \mathrm{m}$ filter and washed with DMEM/high-glucose, followed by centrifugation at $250 \mathrm{~g}$ for $10 \mathrm{~min}$. The cells were then resuspended in complete medium, collected and inoculated into a petri dish. The complete medium contained $10 \%$ inactivated fetal bovine serum (Gibco, Life Technologies) and $1 \%$ penicillin streptomycin (HyClone), the rest of the ingredients is DMEM/high-glucose medium. Cells were stored at $38.5^{\circ} \mathrm{C}$ with saturated humidity, $5 \% \mathrm{CO}_{2}$, and $95 \%$ air. After $1.5 \mathrm{~h}$, the culture medium with cells suspended in the petri dish was collected and re-seeded into a new petri dish. The medium was changed after cultivating for more than $4 \mathrm{~h}$ to obtain relatively pure support cells (Wang et al. 2019a,b).

The NBS cells were cultured in complete medium, and when they reached $60 \%$ confluence, they were cultured for $4 \mathrm{~h}$ in fresh, prewarmed, serum-free high-glucose medium for starvation, then treated with NGF (Recombinant Human beta-Nerve Growth Factor, Novoprotein, Shanghai, China) at $100 \mathrm{ng} / \mathrm{mL}$ for $18 \mathrm{~h}$. The mitogen-activated protein kinase (MAPK) activity inhibitor PD98059 (Beyotime Biotechnology, Shanghai, China; $10 \mu \mathrm{m}$ ), the phosphoinositide 3 kinase (PI3K) activity inhibitor LY294002 (Beyotime Biotechnology, Shanghai, China; $5 \mu \mathrm{m}$ ) and NTRK1 inhibitor K252 $\alpha$ (Invitrogen, Life Technology; $100 \mathrm{ng} / \mathrm{mL}$ ) were also used. These inhibitors were administered $30 \mathrm{~min}$ before NGF was added, and the medium was not changed throughout NGF treatment of the cells, leaving the inhibitors work throughout the period. After $18 \mathrm{~h}$, cells were harvested for quantitative real-time PCR (qRT-PCR) and Western blotting (WB), with three replicates per treatment. All experiments were repeated at least three times.

\section{Cell proliferation assays}

Cell Counting Kit-8 (CCK-8; Beyotime Biotechnology) was used for the cell viability assay. NBS cells were seeded in 96-well plates and cultured in complete medium for $12 \mathrm{~h}$, at which time the cells were completely adherent and had reached $30-40 \%$ confluence. The cells were then incubated in fresh, prewarmed, serum-free medium for $4 \mathrm{~h}$ to complete the starvation treatment, and the cells were treated with different concentrations of NGF for 12, 18, and $24 \mathrm{~h}$. When the cell confluence was about $90 \%, 10 \mu \mathrm{L}$ of CCK-8 reagent was added to each well and the plates were incubated for $2 \mathrm{~h}$ at $37^{\circ} \mathrm{C}$ in darkness. Cell OD (optical density) values were measured using a plate reader ELX 800 Universal Microplate Reader (BioTek) with a wavelength that was set at $450 \mathrm{~nm}$. At this time, the cell viability was directly proportional to OD450. The experiment was repeated at least three times.

\section{Giemsa staining experiment}

The cells were seeded into 12-well plate and stained with Giemsa. Giemsa staining solution (AR-0751, Beijing Dingguo Changsheng Biotechnology Co. Ltd.) was used, and the Giemsa staining procedure was performed in accordance with the manufacturer's instructions. Images were taken under an inverted microscope (Olympus). 


\section{Immunofluorescence}

The cells were washed twice with phosphate buffered saline (PBS, HyClone, South Logan, UT) for 5 min each at room temperature. The cells were then fixed with $4 \%$ paraformaldehyde for $15 \mathrm{~min}$ and washed three times with PBS for 5 min each. Triton X-100 (0.1\%) was added for 10 min to permeabilize the cells, which were then washed three times with PBS for 5 min each. The cells were then blocked with $5 \%$ goat serum for $30 \mathrm{~min}$. The primary antibody FSHR/ NGF/ NTRK1 (1:200, diluted with primary antibody dilution, Bioworld, Nanjing, China) was added and incubated for $16 \mathrm{~h}$ at $4{ }^{\circ} \mathrm{C}$. The cells were then washed three times in PBS for 5 min each. The fluorescein (FITC)-labeled secondary antibody (1:500, diluted in PBS, Bioworld, Nanjing, China) was then added and the cells were incubated at room temperature for $1 \mathrm{~h}$ in darkness. The cells were then washed three times with PBS for 5 min each. PI counterstaining was then performed (1:1000, diluted in PBS) for 10 min, followed by washing three times in PBS for 5 min each. The same volume of PBS was added to each well, and the cell images were taken using an inverted fluorescence microscope (IX71; Olympus).

\section{Transfection with small interfering RNA}

siRNA for NGF and negative control siRNA (siNC) were purchased from Shanghai GeneBio Co., Ltd. (Shanghai, China). The NGF siRNA sequences were 5'-CCAUGUUGU UCUACACUCU-3' and 5'-AGAGUGUAGAACAACAUGG-3'. The siNC sequences were $5^{\prime}$-UUCUCCGAACGUGUCACGU3' and 5'-ACGUGACACGUUCGGAGAA-3'. NBS cells were seeded in 12-well plates and cultured in complete medium to achieve $60 \%$ confluence. NGF siRNA was transfected with FuGENE® HD (Roche) at a concentration of $50 \mathrm{nM}$ in accordance with the manufacturer's protocol. After $36 \mathrm{~h}$, cells were harvested for continued experiments.

\section{RNA preparation and $q R T-P C R$ analysis}

Total RNA was obtained using an RNA isolation system (SigmaAldrich), and then the previously mentioned extracted RNA was reverse transcribed using a PrimeScript RT kit with gDNA removal function (Takara Bio). For cDNA, the experimental procedure was performed in strict accordance with the manufacturer's instructions. The total qRT-PCR reaction system was $20 \mu \mathrm{L}$, containing $10 \mu \mathrm{L}$ SYBR (Takara Bio), $0.5 \mu \mathrm{M}$ for the forward primer, $0.5 \mu \mathrm{M}$ for the reverse primer, $5 \mathrm{ng} / \mu \mathrm{L}$ for the cDNA, and $20 \mu \mathrm{L}$ supplemented with sterile ultrapure water. The reaction conditions were as follows: $95^{\circ} \mathrm{C}$ for $2 \mathrm{~min}, 95^{\circ} \mathrm{C}$ for $15 \mathrm{~s}$, and $60^{\circ} \mathrm{C}$ for $30 \mathrm{~s}$ for 40 cycles. The $2^{-\Delta \Delta \mathrm{Ct}}$ method was used to calculate the relative expression of genes. The primers were synthesized from KuMei, Changchun, China (Table 1).

\section{Western blotting analysis}

Total protein was extracted using WBIP lysis buffer (Cell lysis buffer for Western blot and immunol precipitation) (Beyotime Biotechnology) containing $1 \mathrm{mM}$ of PMSF. The total protein concentration of the samples was measured using a BCA (Bicinchoninic acid) Protein Assay Kit (Beyotime Biotechnology), and the concentration of each protein sample was adjusted to be uniform, based on the measured total protein concentration. The sample total protein was separated by $12 \%$ SDS-PAGE, then transferred to a polyvinylidene difluoride (PVDF, Roche; $0.45 \mu \mathrm{m}$ ) membrane using a semiwet transfer system, and the PVDF membrane was blocked with $5 \%$ BSA for $1 \mathrm{~h}$. BSA (Albumin Bovine V, Guangzhou saiguo biotech Co., Ltd, Guangzhou, China) was diluted with TBST (Monad Biotech Co., Ltd, Shanghai, China). The monoclonal antibodies CCNE2 (1:1000, Bioworld), PCNA (1:1000, Bioworld), NGF (1:1000, Bioworld), NTRK1 (1:1000, Bioworld), INHBB (1:1000, Bioworld), CCND1 (1:1000), VCL (1:1000, Bioworld), t- ERK (1:1000, Bioworld), p-ERK (1:1000, Bioworld), AKT (1:1000, Bioworld), P-AKT (1:1000, Bioworld), and GAPDH (1:8000, Bioworld) were diluted with the quick-block Western primary antibody diluent (Beyotime Biotechnology). The membrane was incubated with the diluted specific antibody for $16 \mathrm{~h}$ at $4^{\circ} \mathrm{C}$. Then, the PVDF membrane was washed four times with TBST for 9 min each. The PVDF membrane was incubated with HRP-labeled secondary antibody $(1: 10,000$, Bioworld) for $1 \mathrm{~h}$ at room temperature. The secondary antibody was diluted with the quick-block Western secondary antibody diluent (Beyotime Biotechnology). Subsequently, the membrane was washed four times with TBST for 9 min each. The BeyoECL Plus kit (Beyotime Biotechnology) was used for protein development. Finally, the relative protein levels were analyzed by grayscale scanning using a Tanon gel imaging system (Tanon, Shanghai, China).

Table 1 Primer sequences used in qRT-PCR.

\begin{tabular}{lll}
\hline Names & Forward sequences $\left(5^{\prime} \rightarrow 3^{\prime}\right)$ & Reverse sequences $\left(5^{\prime} \rightarrow 3^{\prime}\right)$ \\
\hline$G A P D H$ & ACGGCACAGTCAAGGCAGAG & GTGATGGCGTGGACAGTGGT \\
GDNF & GCAGCCGAAACAATGTACGA & AAGGCGATGGGTCTGCAA \\
$S C F$ & ATTGGTGGCAAATCTTCCCA & TGCACTCCACAAGGTCATCAA \\
$C C N E 2$ & GCTGCTGCTGCCTTATGC & TCTGTATGTTGTTCTGTCTTCC \\
$P C N A$ & GTAATGTTGATAAAGAGGAGGAAG & GTAGGAGACAGTGGAGTGG \\
$C C N D 1$ & AACGGCTTCCTCTCCTATC & TCCTCCTCCTCCTCTTCC \\
$I N H B B$ & CTCATCCCTCTCCTTTCACTC & ATGTTCTGCCCATCGTCATAG \\
$V C L$ & GCCTCCATAGACTCCAAACTG & CACCAACTTTCCAGCTTCATC \\
NGF & TCAACAGGACTCACAGGAGCAA & ACCTCTCCCAGCACCATCAC \\
\hline
\end{tabular}

CCND1, cyclin D1; CCNE2, cyclin E2; GAPDH, glyceraldehyde 3-phosphate dehydrogenase; GDNF, glial cell line-derived neurotrophic factor; $I N H B B$, Inhibin subunit beta $B ; N G F$, nerve growth factor; $P C N A$, proliferating cell nuclear antigen; $S C F$, stem cell factor; VCL, vinculin. 


\section{Statistical analysis}

All experiments were repeated at least three times. All data were analyzed using a one-way ANOVA and independentsample $t$-tests. IBM SPSS Statistics 22.0 software (version X, IBM) was used for the analysis, and the difference between the control and treatment groups was tested using Dunnett's multiple comparison. The data from the previously mentioned analysis were compiled using GraphPad Prism 6.0 software. Data are expressed as the mean \pm S.D. of three independent processes. Additionally, '*' means $P<0.05$, which denotes a significant difference; ' $* *$ ' denotes $P<0.01$, and '***' means $P<0.001$, which indicates that the difference is extremely significant.

\section{Results}

\section{NGF and TrkA expression in NBS cells}

Giemsa staining revealed the presence of satellite chromocenters in the NBS cells nuclei (Fig. 1A). Additionally, NBS cells were verified by two genes (GDNF, glial cell line-derived neurotrophic factor and SCF, stem cell factor) biomarkers used for Sertoli cells (Yao et al. 2016) (Fig. 1B).

FSHR expression was demonstrated in NBS cells using immunofluorescence (Fig. 1C). Counting the FSHR-expressing cells in the sample (approximately 100 cells per area counted) showed that $96.0 \pm 1.0 \%$ of the


Negative Control
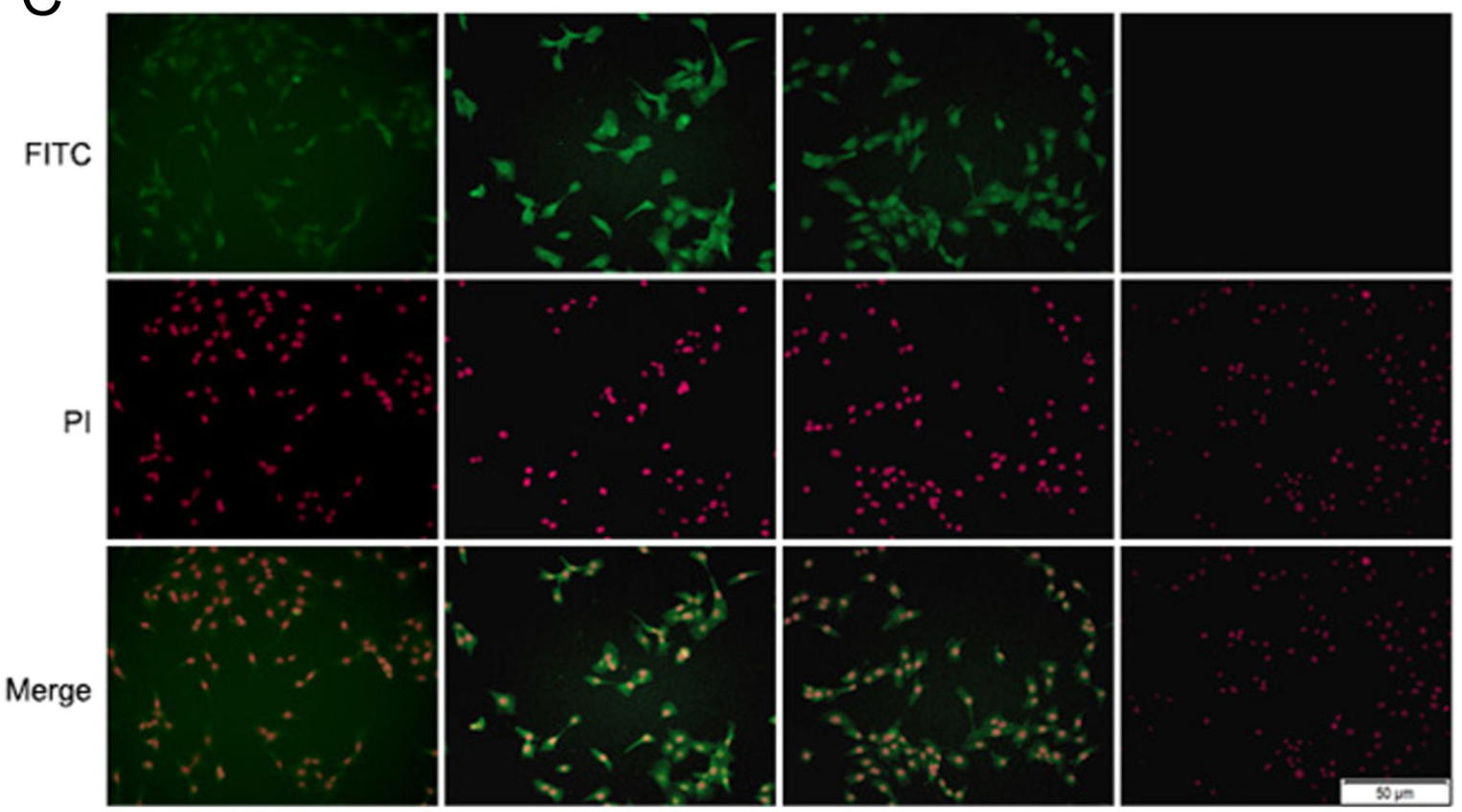

Figure 1 Identification of NBS cells and NGF and NTRK1 expression in cells. (A) Giemsa staining showed the presence of chromocenters around the nucleolus. (B) GDNF and SCF molecular markers were detected in Sertoli cells. (C) The expression of FSHR, NGF and NTRK1 in NBS cells was identified by Immunofluorescence. Scale $=50 \mu \mathrm{m}$. GAPDH, glyceraldehyde 3-phosphate dehydrogenase; GDNF, glial cell line-derived neurotrophic factor; SCF, stem cell factor; FSHR, follicle-stimulating hormone receptor; NGF, nerve growth factor; NTRK1, tyrosine kinase receptor $\mathrm{A}$; Pl, Propidium lodide; FITC, Fluorescein isothiocyanate isomer. 
Table 2 Data analysis of positive cells.

\begin{tabular}{lccc}
\hline & Total cells & Positive cells & $\begin{array}{c}\text { Percentage of positive } \\
\text { cells }(\%)\end{array}$ \\
\hline Sample 1 & 83 & 80 & 96.4 \\
Sample 2 & 102 & 99 & 97.1 \\
Sample 3 & 93 & 89 & 95.7 \\
Sample 4 & 115 & 109 & 94.8 \\
Mean (\%) & & & 96.0 \\
S.D. & & & 1.0
\end{tabular}

cells were FSHR-expressing Sertoli cells (Table 2). All the previously mentioned experiments confirmed that the cells we used are bovine testicular Sertoli cells that can be used for the following experiments. Further, the expression of NGF and NTRK1 in NBS cells was shown using immunofluorescence (Fig. 1C).

\section{Effect of NGF on NBS cells proliferation}

NGF affected cell viability in a concentration-dependent manner. The largest increase in cell proliferation was observed with treatment with NGF at $100 \mathrm{ng} / \mathrm{mL}$ for $18 \mathrm{~h}$ (Fig. 2A). The cell proliferation-related genes CCNE2, $P C N A$, and CCND1 were up-regulated after NGF treatment, and $I N H B B$, which was secreted by the cells, and $V C L$ were also up-regulated (Fig. $2 B$ and $C$ ).

\section{The effect of NGF knockdown on NBS cells proliferation}

The results from qRT-PCR and WB indicated that the level of endogenous NGF expression in the cells was effectively reduced with siRNA of NGF (siNGF) (Fig. $3 \mathrm{~A}$ and $\mathrm{B})$. The cell viability was detected by CCK-8, showing that the cell viability was significantly reduced after adding siNGF (Fig. 3C). Changes in expression of genes for CCNE2, PCNA, and CCND1, INHBB, and VCL after NGF reduction were detected in the levels of $\mathrm{mRNA}$ and protein using qRT-PCR and WB, respectively, and it was found that expression levels of all these genes decreased significantly (Fig. 3D and E).

\section{Effect of NGF on cell proliferation via NTRK1}

The results showed that the cell viability was significantly reduced after $\mathrm{K} 252 \alpha$ treatment, but the viability of the cells in the group that NGF was added 30 min after K252 $\alpha$ addition (NGF-K252 $\alpha$ group) was increased compared with the K252 $\alpha$ group (Fig. 4A). Additionally, the expression levels of CCNE2, PCNA, and CCND1, $I N H B B$ and $V C L$ were significantly decreased after the inhibitor treatment. But in the NGF-K252 $\alpha$ group, the gene expression levels were relatively increased (Fig. 4B and C).

\section{PI3K/AKT signaling pathway participates in the NGF induced cell proliferation, INHBB secretion and ectoplasmic specialization of NBS cells}

NBS cells were treated with NGF for different time periods, and the proportion of phosphorylated cells in the treated cells was assessed (Fig. 5A). Results showed that NGF significantly induced AKT phosphorylation. Then we selected the PI3K/AKT signaling pathway inhibitor LY294002 to treat NBS cells. NBS cells were treated with LY294002, NGF, or both (Fig. 5B), and the viability of cells treated with LY194002 alone was significantly lower compared with the negative control group. The cell viability of the combined treatment group was significantly lower compared with the NGF treatment
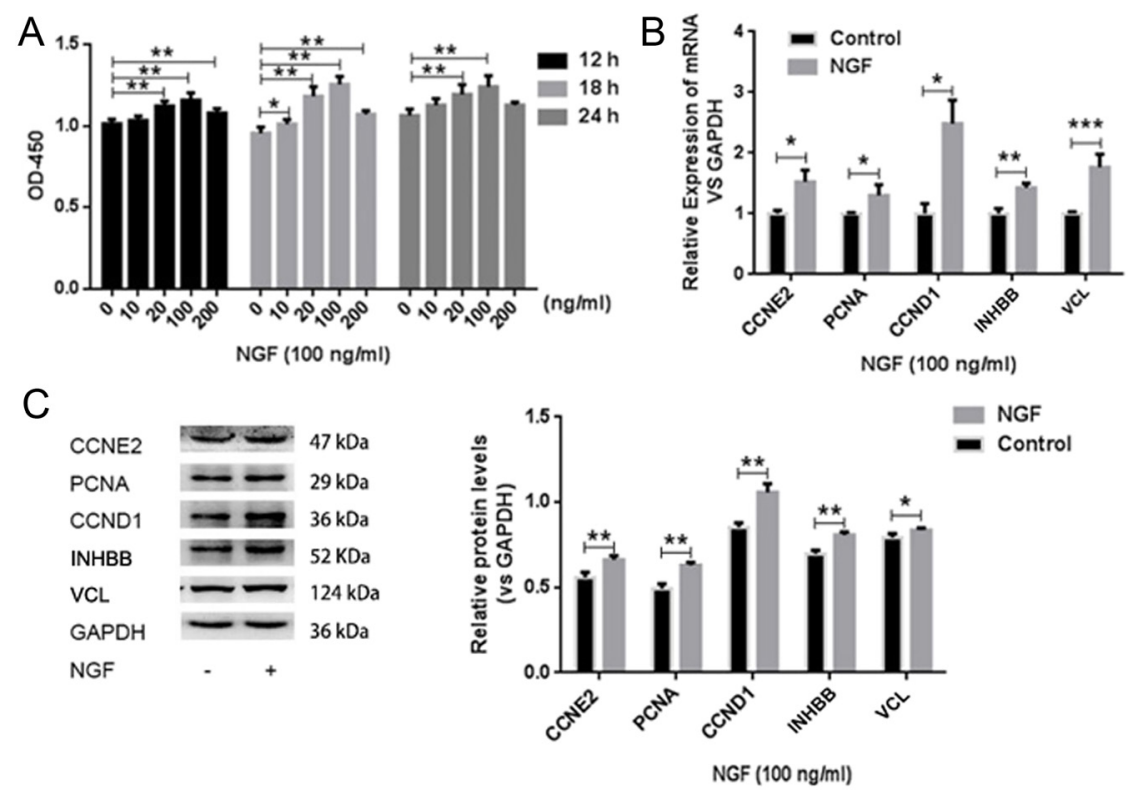

Figure 2 Effect of exogenous NGF on NBS cells proliferation. (A) The effect of NGF on the viability of NBS cells is concentration dependent. (B) The mRNA levels of CCNE2, $P C N A, C C N D 1, I N H B B, V C L$ were significantly increased after NGF treatment. (C) NGF treatment significantly increased the protein levels of CCNE2, PCNA, CCND1, INHBB, VCL in NBS cells. ${ }^{*} P<0.05$, $* * P<0.01,{ }^{* * *} P<0.001$. 

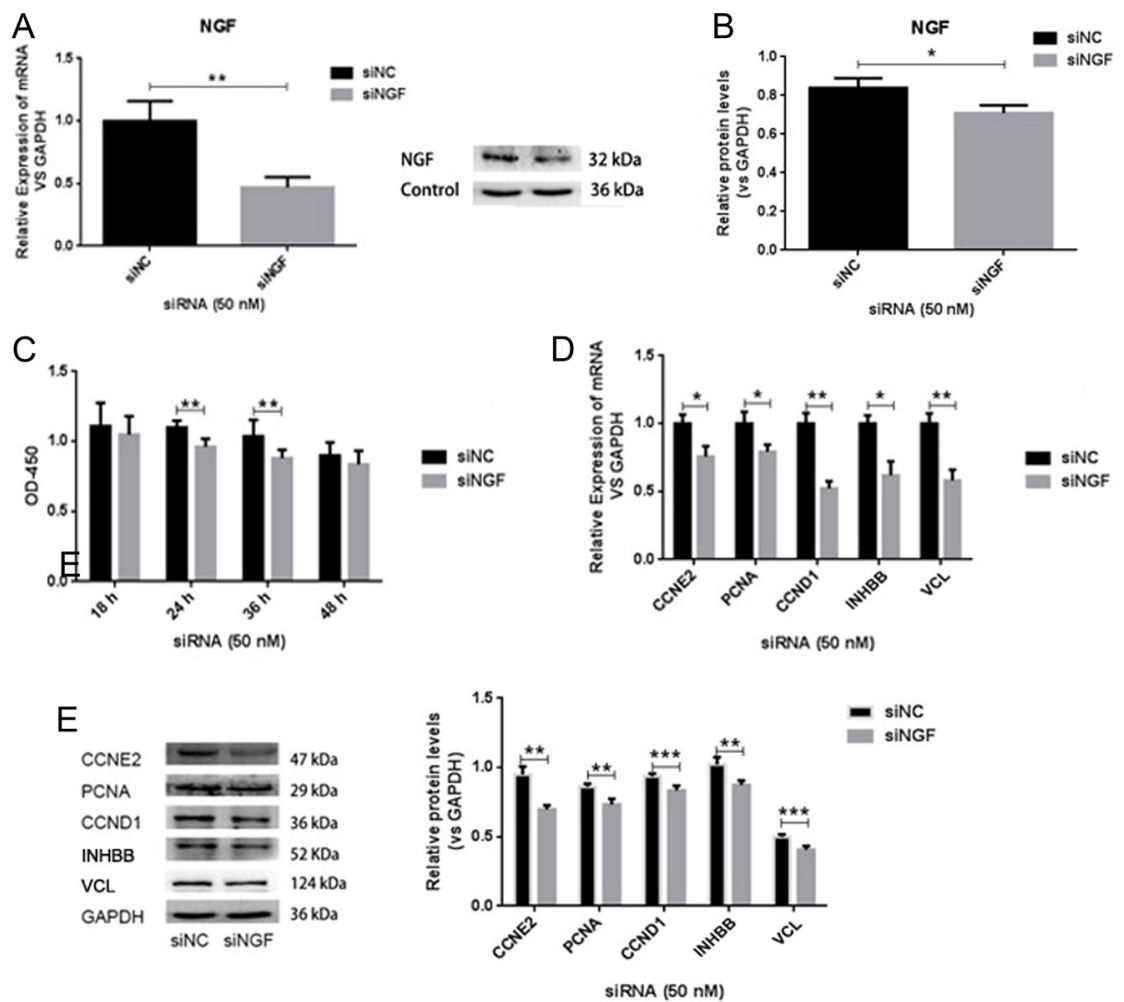

Figure 3 The effect of si-NGF on NBS cells proliferation. (A) The expression of NGF in cells is significantly reduced at the mRNA level. (B) Western blot analysis of siNGF transfected NBS cells significantly reduced the amount of NGF protein in cells. (C) Knockdown NGF in NBS cells reduced the cell viability. (D) The mRNA levels of CCNE2, $P C N A, C C N D 1, I N H B B$, and VCL were significantly decreased at mRNA level after siNGF transfection of NBS cells. (E) Western blot showed that the expression of CCNE2, PCNA, CCND1, INHBB and VCL protein decreased significantly after transfected siNGF in NBS cells. ${ }^{*} P<0.05,{ }^{* *} P<0.01$, $* * * P<0.001$.

alone. This indicated that LY194002 successfully inhibited the intracellular PI3K/AKT signaling pathway.

The expression changes of cell proliferation-related genes CCNE2, PCNA, and CCND1, INHBB, and the ES-related gene $V C L$ were investigated with qRT-PCR and WB (Fig. 5C, D and E). The expression levels of CCNE2, CCND1, INHBB, and VCL were significantly decreased after the PI3K/AKT signaling pathway was inhibited. However, the PCNA expression was not changed (Fig. 5D).

\section{The MAPK/ERK signaling pathway is involved in the effect of NGF on cell proliferation}

To determine whether MAPK/ERK is involved in the regulation of proliferation and cell function by NGF in NBS cells, NBS cells were treated with NGF for different times and the changes in p-ERK and t-ERK expression levels were detected(Fig. 6A). NGF activated MAPK/ ERK phosphorylation and increased p-ERK expression. Figure 6 shows that the level of cell phosphorylation

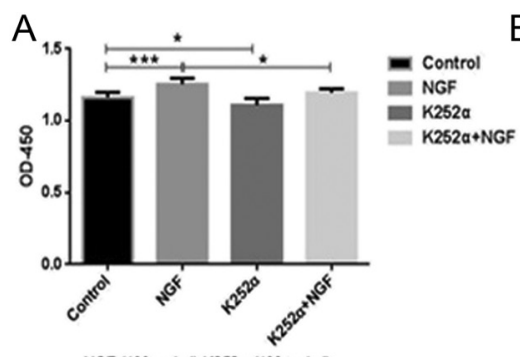

NGF (100 ng/ml) K252a (100 ng/ml)

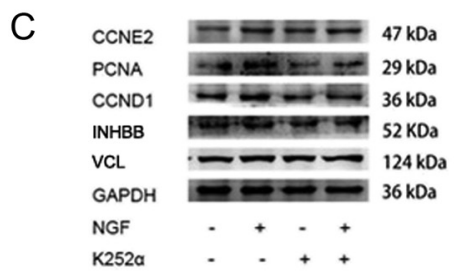

$\mathrm{B} s$

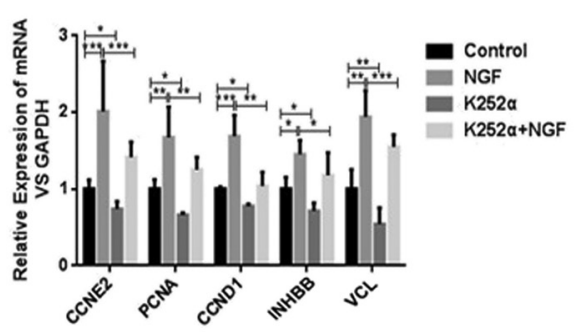

NGF $(100 \mathrm{ng} / \mathrm{ml})$ K252a $(100 \mathrm{ng} / \mathrm{ml})$

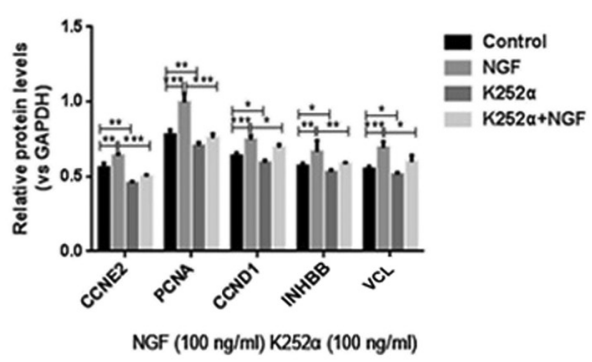

Figure 4 Addition of NTRK1 inhibitor K252 $\alpha$ to detect effect of NGF on NBS cells proliferation. (A) Treatment of cells with the NTRK1 inhibitor K252 $\alpha$ significantly reduced cell viability. (B) The mRNA levels of CCNE2, $P C N A$, and $C C N D 1, I N H B B$ and $V C L$ were significantly decreased after K252 $\alpha$ treatment. (C) Western blot showed that K252a significantly reduced the expression of CCNE2, PCNA, CCND1, INHBB, and VCL. ${ }^{*} P<0.05,{ }^{* *} P<0.01,{ }^{* * *} P<0.001$. 
A

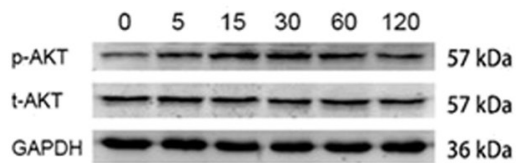

$\mathrm{B}$
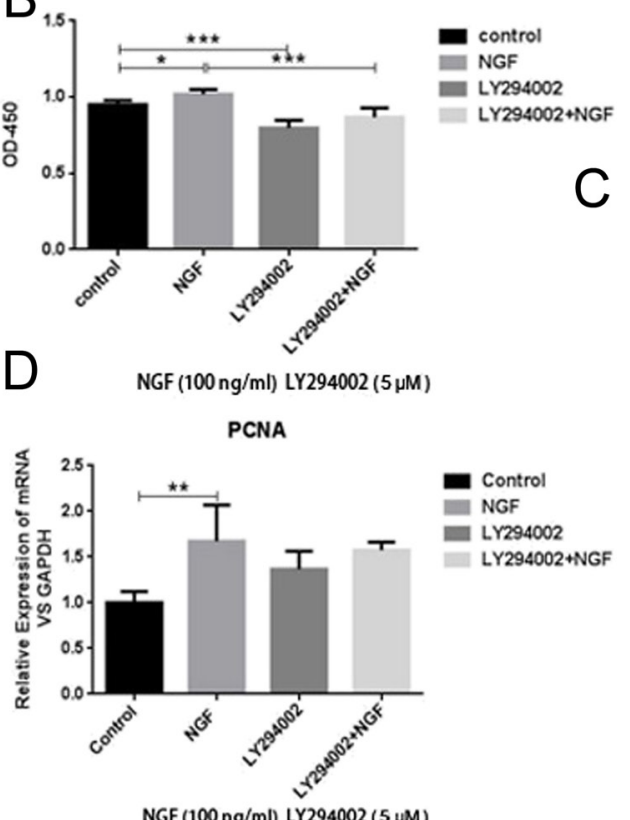

NGF (100 ng/ml) LY294002 (5 pM)

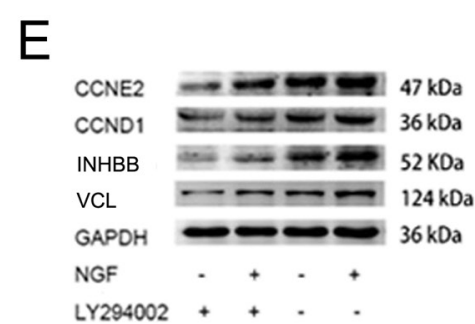

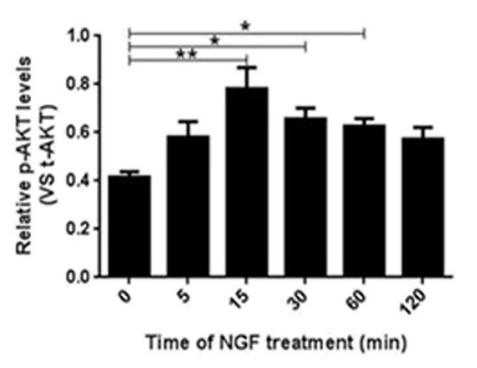
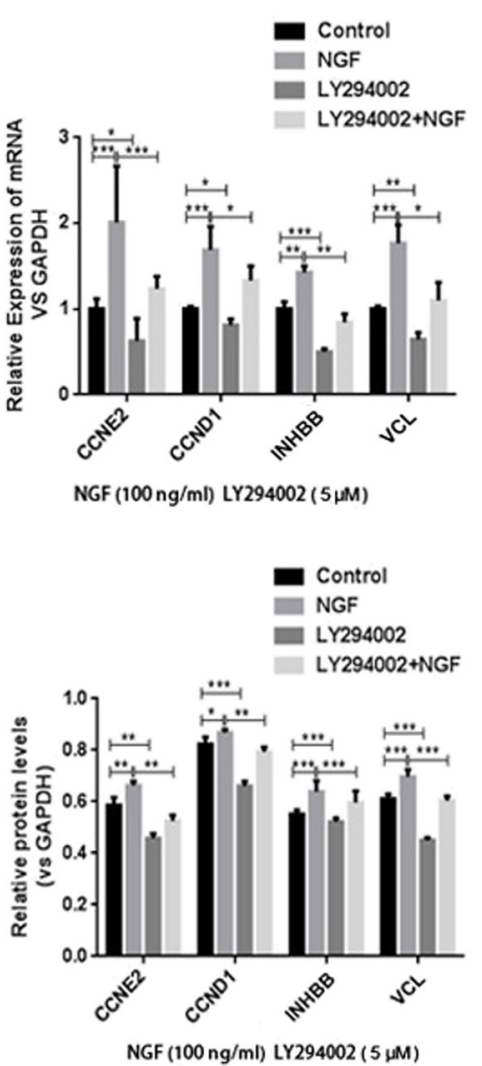

Figure $5 \mathrm{PI} 3 \mathrm{~K} / \mathrm{AKT}$ is activated by NGF and involved in the regulation of NBS cells proliferation induced by NGF. (A) NGF activated AKT phosphorylation at a timedependent manner. (B) PI3K/AKT signaling pathway inhibitor LY294002 attenuated the cell viability induced by NGF. (C) LY294002 decreased the mRNA levels of CCNE2, CCND1, INHBB, and VCL regulated by NGF. (D) The expression of PCNA at the mRNA level was not reduced by the addition of LY294002. (E) Western blot analysis showed that the blockade of PI3K/AKT signaling pathway significantly reduced the expression of CCNE1, CCND1, INHBB, and VCL regulated by NGF. ${ }^{*} P<0.05,{ }^{* *} P<0.01,{ }^{* * *} P<0.001$. was significantly increased after 15 min or 30 min of NGF treatment. Then PD98059 (a MAPK inhibitor) was selected to treat the cells and cell viability was significantly reduced (Fig. 6B). Using NGF alone or in combination with PD98059, the expressions of CCNE2, PCNA, CCND1 and INHBB showed a significant decrease resulting from the addition of the inhibitor, but the expression of $V C L$ did not change significantly after signal pathway inhibition (Fig. 6C, D and E).

\section{Discussion}

NGF, the first discovered member of the neurotrophins family, is expressed in multiple systems other than the nervous system. In previous studies, immunohistochemistry results showed the presence of NGF and its high-affinity receptor NTRK1 in various cells in the testis during the breeding and non-breeding seasons (Jin et al. 2006, Wang et al. 2011, Zhang et al. 2015). The quantitative results showed that the NGF in the human testis was $5.4 \mathrm{ng} / \mathrm{g}$ and that NGF affected the morphology and function of the seminiferous tubules that were cultured in vitro (Seidl \& Holstein 1990). Sertoli cells secrete NGF as a growth factor which maintains the vitality of Sertoli cells and promotes the normal development of the perinatal male fetal testes (Seidl et al. 1996, Skinner 2005). In vitro studies have shown that exogenous NGF can increase cell viability and sperm motility. Thus, NGF may participate in regulating sperm function by paracrine way (Naraballobh et al. 2010, Jiang et al. 2018).

NGF promotes cell proliferation in neuronal cells, such as Müller cells and oligodendrocytes, and in many other types of cells, such as vascular endothelial cells, myoblasts, and keratinocytes (Althaus et al. 1992, Wang et al. 2016). Moreover, most published studies report that NGF promotes cell proliferation through 

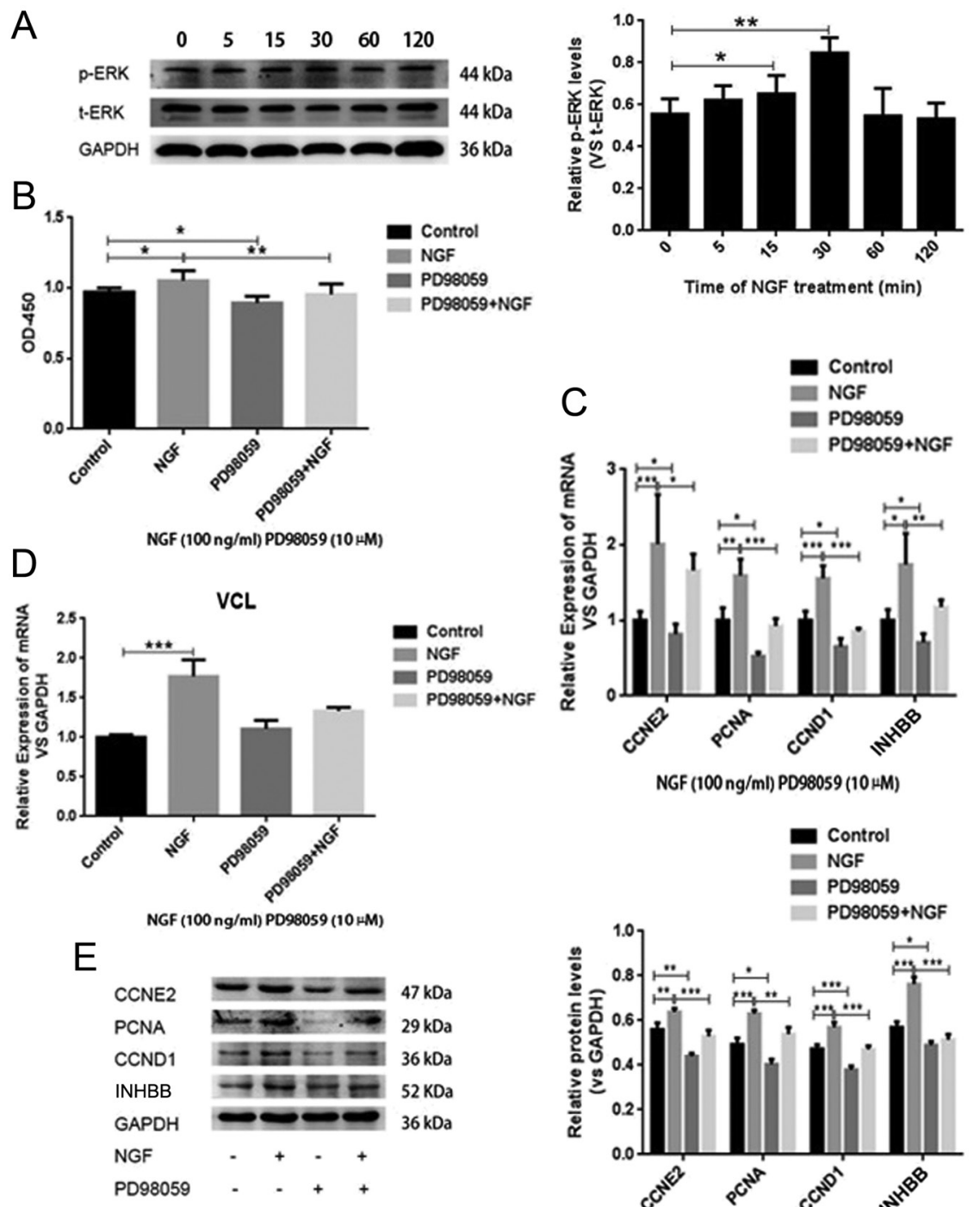

Figure $6 \mathrm{MAPK} / \mathrm{ERK}$ signaling pathway is activated by NGF and involved in the NGF-induced NBS cells proliferation. (A) Western blot results showed that NGF could activate ERK phosphorylation in NBS cells. (B)

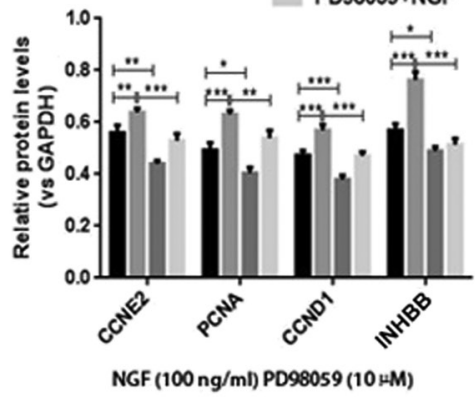
PD98059 (a MAPK inhibitor) attenuated the NGF-induced cell viability. (C) PD98059 decreased the mRNA level of CCNE2, PCNA, $C C N D 1$, and INHBB induced by NGF. (D) qPCR results showed that vinculin expression was not decreased after blocking of ERK signaling pathway in NBS cells. (E) Western blot showed that CCNE2, PCNA, CCND1, and INHBB were significantly decreased in NBS cells after PD98059 treatment. ${ }^{*} P<0.05$, ${ }^{* *} P<0.01,{ }^{* * *} P<0.001$.

its high affinity receptor NTRK1 (Rende et al. 2000, Raychaudhuri et al. 2001, Paus et al. 1994). While investigating the NGF mechanism of action on Sertoli cells, we screened the proliferation-related genes CCNE2, CCND1, and PCNA. CCNE2 (cyclin E2) and CCND1 (cyclin D1) are cyclins that regulate the transition from G1 to $S$ phase in the mitotic cell cycle and promote cell proliferation (Chen et al. 2019). PCNA (proliferating cell nuclear antigen) is a hallmark of cell proliferation and it is closely related to cellular DNA synthesis (Dietrich 1993, Mcneal et al. 1995). Both mRNA and protein levels of genes associated with cell proliferation were detected after NBS were treated with exogenous NGF or transfected with siRNA of NGF (siNGF). It was found that NGF promoted expression of the proliferation genes, CCNE2, CCND1, and PCNA. To demonstrate whether the effect of NGF on NBS cells occurs through its receptor NTRK1, the NTRK1 inhibitor K252 $\alpha$ was used to treat the cells. The results showed that NGF promoted NBS cells proliferation through the NTRK1 receptor.

Sertoli cells are thought to contain unique satellite chromocenters in their nuclei (Raychoudhury \& Kubinski 2003, França et al. 2016). The mouse satellite DNA sequence was located in the centromeric chromosomal heterochromatin. In the adult Sertoli cells of most mouse strains, all centromere heterochromatin is concentrated in two chromocenters on the sides of the nucleolus. Chromocenters are the hallmark structures of the interphase nuclei of constitutive heterochromatin (Pardue \& Gall 1970, Jean et al. 1983, Kuznetsova et al. 2016). Evidence also suggests that satellite DNA is present in bovine cells (Streeck and R. 1981, Pages \& Roizes 1982). In this experiment, satellite chromocenters were successfully detected in NBS cells.

In males, INHBB is mainly derived from testicular Sertoli cells, which can negatively regulate pituitary 


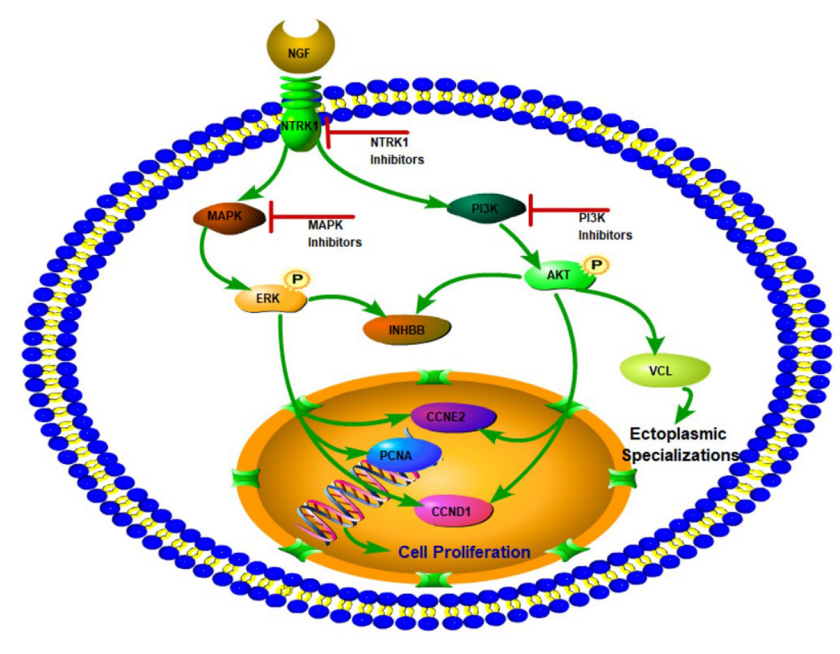

Figure 7 Flowchart of overall description of the effect of NGF on NBS cells proliferation. NGF activates two molecular signaling pathways, PI3K/AKT and MAPK/ERK, through its high-affinity receptor NTRK1. Activation of the AKT signaling pathway affects the expression of CCNE2, CCND1, INHBB and VCL and promotes the cell proliferation. Meanwhile, activation of MAPK/ERK promotes the expression of CCNE2, PCNA, CCND1 and INHBB and increased the cell proliferation and inhibin secretion.

FSH release and coordinate sexual development. When the function of Sertoli cells is impaired, there will be an increase in FSH and a decrease in inhibin. Therefore, serum INHBB levels have now been used as an indicator of normal testicular function in males (Mather et al. 1992, Klingmuller \& Haidl 1997). Studies have shown that a variety of growth factors in testis are involved in regulating the proliferation and functions of Sertoli cells. It has been proven that NGF can nourish Sertoli cells and increase cell viability (Chen et al. 1997). However, the interaction between NGF and INHBB remains to be elucidated. Based on previous studies, NGF can stimulate FSHR expression in follicles in female ovaries (Julio-Pieper et al. 2006), and it is known that follicular growth is controlled by FSH that is secreted by the pituitary. FSH stimulates granulosa cells in the follicle to produce estradiol and inhibin A and B. Subsequently, the accumulation of estradiol and inhibin $A$ and $B$ in the follicle increased. Negative feedback also regulates the production of pituitary FSH (Hale et al. 2014). Therefore, we speculate that there may be a regulatory relationship between NGF and inhibin A and $B$ in females. In this experiment, we explored the effect of NGF on INHBB in Sertoli cells and found that NGF can positively regulate INHBB.

In the testes, there are many forms of adhesion junctions in Sertoli cells. ES is an atypical cell junction, which is observed by VCL and actin immunohistochemical colocalization and can link Sertoli cells to Sertoli cells or Sertoli cells to spermatids (Pfeiffer \& Vogl 1991). VCL is a common cytoskeletal protein that is expressed in a variety of cells. In previous studies, VCL was found to be involved in neuronal synapses and elongation in PC12 cells and it can be phosphorylated and recombined in response to NGF regulation (Halegoua 1987, VarnumFinney \& Reichardt 1994). The data from the present study showed that NGF promotes the expression of VCL gene at the mRNA and protein levels via the receptor NTRK1 and that this process requires the involvement of the MAPK/AKT signaling pathway.

The PI3K/AKT pathway is an important molecular pathway in cells, and it is involved in the regulation of cell proliferation and apoptosis. Studies have shown that the PI3K/AKT pathway is involved in the proliferation of adult hippocampal neural progenitor cells (Peltier et al. 2007). Our results indicate that the AKT signaling pathway is involved in the regulation of CCNE2, CCND1, INHBB, and VCL by NGF, while the regulation of PCNA by NGF does not depend on the AKT pathway (Fig. 7). When a cell develops a proliferative phenotype, another pathway in the cell that is closely related to proliferation also comes to mind: the MAPK/ERK pathway. When ERK is activated, many factors in the cell become phosphorylated, induce early gene production, and promote cell proliferation (Lewis et al. 1998). In NBS cells, NGF-induced expression of CCNE2, PCNA, CCND1, and INHBB was regulated by ERK pathway (Fig. 7). Studies have reported that NGF can affect cell proliferation by activating AKT and ERK pathways in different cell types. NGF promotes fibroblast proliferation to accelerate skin wound healing (Chen et al. 2014). NGF accelerates cell cycle progression in human corneal epithelial cells by regulating D-type cyclins and promotes corneal wound healing and regulates the proliferation of retinal Müller cells (Hong et al. 2012, Wang et al. 2016).

In conclusion, the results showed that NGF activates PI3K/ATK and MAPK/ERK signaling pathways via its receptor NTRK1, promotes the expression of cell proliferation related genes CCNE2, PCNA, CCND1 and cell function related genes $I N H B B$ and $V C L$, and promotes the proliferation of NBS cells (Fig. 7). This study will help to understand the role of NGF in male reproduction and provide a potential therapeutic target for diseases such as testicular hypoplasia and spermatogenesis disorders caused by abnormal testicular Sertoli cells.

\section{Declaration of interest}

The authors declare that there is no conflict of interest that could be perceived as prejudicing the impartiality of the research reported.

\section{Funding}

This work was supported by The National Natural Science Foundation of China (31672417, 31772596, and 31872983); 
Jilin Provincial Department of Education Project (grant numbers: JJKH20190176KJ).

\section{Data availability statement}

There is no data source for data used in this article and the data involved are original and available on reasonable request.

\section{Author contribution statement}

The study was designed by Chunjin Li, Xu Zhou and Qiaoge Niu and was performed by Qiaoge Niu, Maosheng Cao, Chenfeng Yuan, Yuwen Huang, Zijiao Zhao, Boqi Zhang, Xin Wang, Yameng Wei and Wenjing Fan. All authors read and approved the final version of the manuscript.

\section{Acknowledgements}

The authors thank all the paper participants for their contributions to this paper and the College of Animal Science of Jilin University for the equipment support provided for this experiment. The authors thank the language editor from Liwen Bianji, Edanz Editing China (www.liwenbianji.cn/ac), for editing the English text of a draft of this manuscript.

\section{References}

Althaus HH, Klöppner S, Schmidt-Schultz T \& Schwartz P 1992 Nerve growth factor induces proliferation and enhances fiber regeneration in oligodendrocytes isolated from adult pig brain. Neuroscience Letters $\mathbf{1 3 5}$ 219-223. (https://doi.org/10.1016/0304-3940(92)90440-i)

Attiah DG, Kopher RA \& Desai TA 2003 Characterization of PC12 cell proliferation and differentiation-stimulated by ECM adhesion proteins and neurotrophic factors. Journal of Materials Science: Materials in Medicine 14 1005-1009. (https://doi.org/10.1023/a:1026363018805)

Cantarella G, Lempereur L, Presta M, Ribatti D, Lombardo G, Lazarovici P, Zappala G, Pafumi C \& Bernardini R 2002 Nerve growth factorendothelial cell interaction leads to angiogenesis in vitro and in vivo. FASEB Journal 16 1307-1309. (https://doi.org/10.1096/fj.01-1000fje)

Chen Y, Dicou E \& Djakiew D 1997 Characterization of nerve growth factor precursor protein expression in rat round spermatids and the trophic effects of nerve growth factor in the maintenance of Sertoli cell viability. Molecular and Cellular Endocrinology 127 129-136. (https:// doi.org/10.1016/s0303-7207(96)04001-4)

Chen JC, Lin BB, Hu HW, Lin C, Jin WY, Zhang FB, Zhu YA, Lu CJ, Wei XJ \& Chen RJ 2014 NGF accelerates cutaneous wound healing by promoting the migration of dermal fibroblasts via the PI3K/Akt-Rac1-JNK and ERK pathways. BioMed Research International 2014 547187. (https://doi. org/10.1155/2014/547187)

Chen S, Wang F, Liu Z, Zhao Y, Jiang Y, Chen L, Li C \& Zhou X 2019 Brain-derived neurotrophic factor promotes proliferation and progesterone synthesis in bovine granulosa cells. Journal of Cellular Physiology 234 8776-8787. (https://doi.org/10.1002/jcp.27536)

Chui K, Trivedi A, Cheng CY, Cherbavaz DB, Dazin PF, Huynh AL, Mitchell JB, Rabinovich GA, Noble-Haeusslein LJ \& John CM 2011 Characterization and functionality of proliferative human Sertoli cells. Cell Transplantation 20 619-635. (https://doi.org/10.3727/096368910X536563)

Dietrich DR 1993 Toxicological and pathological applications of proliferating cell nuclear antigen (PCNA), a novel endogenous marker for cell proliferation. Critical Reviews in Toxicology 23 77-109. (https:// doi.org/10.3109/10408449309104075)

França L R, Hess R A, Dufour J M, Hofmann M C \& Griswold M D 2016. The Sertoli cell: one hundred fifty years of beauty and plasticity. Andrology 4 189-212. (https://doi.org/10.1111/andr.12165)
Griswold MD 1998 The central role of Sertoli cells in spermatogenesis. Seminars in Cell and Developmental Biology 9 411-416. (https://doi. org/10.1006/scdb.1998.0203)

Hale GE, Robertson DM \& Burger HG 2014 The perimenopausal woman: endocrinology and management. Journal of Steroid Biochemistry and Molecular Biology 142 121-131. (https://doi.org/10.1016/j. jsbmb.2013.08.015)

Halegoua S 1987 Changes in the phosphorylation and distribution of vinculin during nerve growth factor induced neurite outgrowth. Developmental Biology 121 97-104. (https://doi.org/10.1016/0012-1606(87)90142-4)

Hipler UC, Hochheim B, Knoll B, Tittelbach J \& Schreiber G 2001 Serum inhibin B as a marker for spermatogenesis. Archives of Andrology $\mathbf{4 6}$ 217-222. (https://doi.org/10.1080/01485010151096540)

Hong J, Qian T, Le Q, Sun X, Wu J, Chen J, Yu X \& Xu J 2012 NGF promotes cell cycle progression by regulating D-type cyclins via PI3K/Akt and MAPK/Erk activation in human corneal epithelial cells. Molecular Vision 18 758-764.

Illingworth PJ, Groome NP, Byrd W, Rainey WE, Mcneilly AS, Mather JP \& Bremner WJ 1996 Inhibin-B: a likely candidate for the physiologically important form of inhibin in men. Journal of Clinical Endocrinology and Metabolism 81 1321-1325. (https://doi.org/10.1210/ jcem.81.4.8636325)

Jain M \& Halder A 2012 Sertoli cell only syndrome: status of Sertoli cell maturation and function. Indian Journal of Endocrinology and Metabolism 16 S512-S513. (https://doi.org/10.4103/2230-8210.104154)

Jean P, Hartung M, Mirre C \& Stahl A 1983. Association of centromeric heterochromatin with the nucleolus in mouse Sertoli cells. Anatomical Record 205 375-380. (https://doi.org/10.1002/ar.1092050402)

Jiang YW, Zhao Y, Chen SX, Chen L, Li CJ \& Zhou X 2018 NGF promotes mitochondrial function by activating PGC-1alpha in TM4 Sertoli cells. Andrologia 50. (https://doi.org/10.1111/and.12837)

Jin W, Arai KY, Shimizu K, Kojima C, Itoh M, Watanabe G \& Taya K 2006 Cellular localization of NGF and its receptors trkA and p75LNGFR in male reproductive organs of the Japanese monkey, Macaca fuscata fuscata. Endocrine 29 155-160. (https://doi.org/10.1385/ ENDO:29:1:155)

Jin W, Tanaka A, Watanabe G, Matsuda H \& Taya K 2010 Effect of NGF on the motility and acrosome reaction of golden hamster spermatozoa in vitro. Journal of Reproduction and Development $\mathbf{5 6}$ 437-443. (https:// doi.org/10.1262/jrd.09-219n)

Julio-Pieper M, Lara HE, Bravo JA \& Romero C 2006 Effects of nerve growth factor (NGF) on blood vessels area and expression of the angiogenic factors VEGF and TGFbeta1 in the rat ovary. Reproductive Biology and Endocrinology 4 57. (https://doi.org/10.1186/1477-7827-4-57)

Klingmuller D \& Haidl G 1997 Inhibin B in men with normal and disturbed spermatogenesis. Human Reproduction 12 2376-2378. (https://doi. org/10.1093/humrep/12.11.2376)

Kuznetsova IS, Ostromyshenskii DI, Komissarov AS, Prusov AN, Waisertreiger IS, Gorbunova AV, Trifonov VA, Ferguson-Smith MA \& Podgornaya O I 2016. LINE-related component of mouse heterochromatin and complex chromocenters' composition. Chromosome Research 24 309-323. (https://doi.org/10.1007/s10577-016-9525-9)

Lewis TS, Shapiro PS \& Ahn NG 1998 Signal transduction through MAP kinase cascades. Advances in Cancer Research 74 49-139. (https://doi. org/10.1016/s0065-230x(08)60765-4)

Li CM, Watanabe G, Weng Q, Jin WZ, Furuta C, Suzuki AK, Kawaguchi M \& Taya K 2005 Expression of nerve growth factor (NGF), and its receptors TrkA and p75 in the reproductive organs of the adult male rats. Zoological Science 22 933-937. (https://doi.org/10.2108/zsj.22.933)

Li C, Sun Y, Yi K, Ma Y, Sun Y, Zhang W \& Zhou X 2010 Detection of nerve growth factor (NGF) and its specific receptor (TrkA) in ejaculated bovine sperm, and the effects of NGF on sperm function. Theriogenology $\mathbf{7 4}$ 1615-1622. (https://doi.org/10.1016/j.theriogenology.2010.06.033)

Maranesi M, Zerani M, Leonardi L, Pistilli A, Arruda-Alencar J, Stabile AM, Rende M, Castellini C, Petrucci L, Parillo F et al. 2015 Gene expression and localization of NGF and its cognate receptors NTRK1 and NGFR in the sex organs of male rabbits. Reproduction in Domestic Animals $\mathbf{5 0}$ 918-925. (https://doi.org/10.1111/rda.12609)

Mather JP, Woodruff TK \& Krummen LA 1992 Paracrine regulation of reproductive function by inhibin and activin. Proceedings of the Society for Experimental Biology and Medicine 201 1-15. (https://doi. org/10.3181/00379727-201-43473) 
Mcneal JE, Haillot O \& Yemoto C 1995 Cell proliferation in dysplasia of the prostate: analysis by PCNA immunostaining. Prostate 27 258-268. (https://doi.org/10.1002/pros.2990270505)

Naraballobh W, Chomdej S, Murani E, Wimmers K \& Ponsuksili S 2010 Annotation and in silico localization of the Affymetrix GeneChip Porcine Genome Array. Archiv Fur Tierzucht 53 230-238.

Pages M \& Roizes G 1982. Tissue specificity and organisation of CpG methylation in calf satellite DNA I. Nucleic Acids Research 10 565-576. (https://doi.org/10.1093/nar/10.2.565)

Pardue M L \& Gall J G 1970. Chromosomal Localization of Mouse Satellite DNA. Science 168 1356-1358. (https://doi.org/10.1126/ science.168.3937.1356)

Parthipan S, Selvaraju S, Somashekar L, Arangasamy A, Sivaram M \& Ravindra JP 2017 Spermatozoal transcripts expression levels are predictive of semen quality and conception rate in bulls (Bos taurus). Theriogenology $98 \quad 41-49$. (https://doi.org/10.1016/j. theriogenology.2017.04.042)

Paus R, Lüftl M . \& Czarnetzki BM 1994 Nerve growth factor modulates keratinocyte proliferation in murine skin organ culture. British Journal of Dermatology 130 174-180. (https://doi.org/10.1111/j.1365-2133.1994. tb02896.x)

Peltier J, O'neill A \& Schaffer DV 2007 PI3K/Akt and CREB regulate adult neural hippocampal progenitor proliferation and differentiation. Developmental Neurobiology 67 1348-1361. (https://doi.org/10.1002/dneu.20506)

Petersen PM, Andersson AM, Rørth M, Daugaard G . \& Skakkebaek NE 1999 Undetectable inhibin B serum levels in men after testicular irradiation. Journal of Clinical Endocrinology and Metabolism 84 213-215. (https://doi.org/10.1210/jcem.84.1.5406)

Pfeiffer DC \& Vogl AW 1991 Evidence that vinculin is co-distributed with actin bundles in ectoplasmic ('junctional') specializations of mammalian Sertoli cells. Anatomical Record 231 89-100. (https://doi.org/10.1002/ ar.1092310110)

Pierik FH, Burdorf A, De Jong FH \& Weber RF 2003 Inhibin B: a novel marker of spermatogenesis. Annals of Medicine 35 12-20. (https://doi. org/10.1080/07853890310004084)

Raychaudhuri SK, Raychaudhuri SP, Weltman H \& Farber EM 2001 Effect of nerve growth factor on endothelial cell biology: proliferation and adherence molecule expression on human dermal microvascular endothelial cells. Archives of Dermatological Research 293 291-295. (https://doi.org/10.1007/s004030100224)

Raychoudhury SS \& Kubinski D 2003. Polycyclic aromatic hydrocarboninduced cytotoxicity in cultured rat Sertoli cells involves differential apoptotic response. Environmental Health Perspectives 111 33-38. (https://doi.org/10.1289/ehp.5458)

Rende M, Brizi E, Conner J, Treves S, Censier K, Provenzano C, Taglialatela G, Sanna PP \& Donato R 2000 Nerve growth factor (NGF) influences differentiation and proliferation of myogenic cells in vitro via TrKA. International Journal of Developmental Neuroscience 18 869-885. (https://doi.org/10.1016/s0736-5748(00)00041-1)

Seidl K \& Holstein AF 1990 Evidence for the presence of nerve growth factor (NGF) and NGF receptors in human testis. Cell and Tissue Research 261 549-554. (https://doi.org/10.1007/BF00313534)

Seidl K, Buchberger A \& Erck C 1996 Expression of nerve growth factor and neurotrophin receptors in testicular cells suggest novel roles for neurotrophins outside the nervous system. Reproduction, Fertility, and Development 8 1075-1087. (https://doi.org/10.1071/rd9961075)

Skinner MK 2005 Sertoli Cell Secreted Regulatory Factors.

Streeck RE 1981. Inserted sequences in bovine satellite DNA's. Science 213 443-445. (https://doi.org/10.1126/science.6264600)

Varnum-Finney B \& Reichardt LF 1994 Vinculin-deficient PC12 cell lines extend unstable lamellipodia and filopodia and have a reduced rate of neurite outgrowth. Journal of Cell Biology 127 1071-1084. (https://doi. org/10.1083/jcb.127.4.1071)

Wang H, Dong Y, Chen W, Hei J \& Dong C 2011 Expression and localization of nerve growth factor (NGF) in the testis of alpaca (Ilama pacos). Folia Histochemica and Cytobiologica 49 55-61. (https://doi. org/10.5603/fhc.2011.0009)

Wang J, He C, Zhou T, Huang Z, Zhou L \& Liu X 2016 NGF increases VEGF expression and promotes cell proliferation via ERK1/2 and AKT signaling in Müller cells. Molecular Vision 22 254-263.

Wang C, Zheng P, Adeniran SO, Ma M, Huang F, Adegoke EO \& Zhang G 2019a Thyroid hormone (T3) is involved in inhibiting the proliferation of newborn calf Sertoli cells via the PI3K/Akt signaling pathway in vitro. Theriogenology 133 1-9. (https://doi.org/10.1016/j. theriogenology.2019.04.025)

Wang X, Adegoke EO, Ma M, Huang F, Zhang $\mathbf{H}$, Adeniran SO, Zheng $\mathbf{P}$ \& Zhang G 2019b Influence of Wilms' tumor suppressor gene WT1 on bovine Sertoli cells polarity and tight junctions via non-canonical Wnt signaling pathway. Theriogenology 138 84-93. (https://doi. org/10.1016/j.theriogenology.2019.07.007)

Wong EW, Mruk DD \& Cheng CY 2008 Biology and regulation of ectoplasmic specialization, an atypical adherens junction type, in the testis. Biochimica et Biophysica Acta 1778 692-708. (https://doi. org/10.1016/j.bbamem.2007.11.006)

Yao C, Sun M, Yuan Q, Niu M, Chen Z, Hou J, Wang H, Wen L, Liu Y, Li Z et al. 2016 MiRNA-133b promotes the proliferation of human Sertoli cells through targeting GLI3. Oncotarget 7 2201-2219. (https://doi. org/10.18632/oncotarget.6876)

Zhang Y, Moheban DB, Conway BR, Bhattacharyya A \& Segal RA 2000 Cell surface Trk receptors mediate NGF-induced survival while internalized receptors regulate NGF-induced differentiation. Journal of Neuroscience 20 5671-5678. (https://doi.org/10.1523/ JNEUROSCI.20-15-05671.2000)

Zhang H, Wang Y, Zhang J, Wang L, Li Q, Sheng X, Han Y, Yuan Z \& Weng Q 2015 Testicular expression of NGF, TrkA and p75 during seasonal spermatogenesis of the wild ground squirrel (Citellus dauricus Brandt). European Journal of Histochemistry 59 2522. (https://doi. org/10.4081/ejh.2015.2522)

Received 10 December 2019

First decision 13 January 2020

Revised manuscript received 14 June 2020

Accepted 18 June 2020 